\title{
INCIDENCE OF MINOR AILMENTS OF PUERPERIUM AND RELATED KNOWLEDGE AMONG POSTNATAL MOTHERS
}

\author{
SOUMYA RAJ K, RESHMA RAJAN, SUVI KJ \\ Department of Obstetrics and Gynecology, Amrita College of Nursing, Amrita University, Kochi, Kerala, India. \\ Email: Reshmarajan66601@gmail.com
}

Received: 30 June 2017, Revised and Accepted: 14 October 2017

\section{ABSTRACT}

Objective: The objective of the study was to identify the incidence and knowledge of minor ailments of puerperium among postnatal mothers and to develop an information leaflet on the management of minor ailments of puerperium.

Methods: A quantitative approach with descriptive design and convenience sampling technique was used in this study. With these methods, the researcher selected 100 postnatal mothers attending Obstetrics and Gynecology ward, AIMS, Kochi. A semi-structured questionnaire along with a checklist was used to assess the knowledge and the incidence of minor ailments among postnatal mothers.

Result: The result showed that the common incidence of minor ailments was afterpain (67\%), perineal discomfort (50\%), constipation (43\%), and fatigue (67\%). Majority of the postnatal mothers had average knowledge (65\%) level, and some of them had good knowledge (21\%), and some of them had poor knowledge (14\%).

Conclusion: The study revealed that the main four problems of minor ailments of puerperium were afterpain, perineal discomfort, constipation, and fatigue. Number of studies from different part of the world, including India, shows that a large proportion of postnatal mother experiences minor ailments of puerperium. This provides evidence for giving importance to minor ailments of puerperium. Researchers also provided a baseline information leaflet on the management of minor ailments of puerperium.

Keywords: Puerperium, Minor ailments, Incidence, Postnatal mother.

(C) 2018 The Authors. Published by Innovare Academic Sciences Pvt Ltd. This is an open access article under the CC BY license (http://creativecommons. org/licenses/by/4. 0/) DOI: http://dx.doi.org/10.22159/ajpcr.2018.v11i1.21022

\section{INTRODUCTION}

Postpartum period or postnatal period is the period beginning immediately after the birth of a child and extending for about 6 weeks [1]. The World Health Organization (WHO) describes the postnatal period as the most critical and yet the most neglected phase in the lives of mothers and babies; most deaths occur during the postnatal period [2]. It is the time after birth, a time in which the mother's body, including hormone levels and uterus size, returns to a nonpregnant state.

Episiotomy refers to incision of the perineum during the second stage of delivery to spread the pelvic outlet and to prevent delay in fetal head delivery. Nowadays, episiotomy is not a popular method in developed countries but is routinely used in Asian countries where women have short perineum and strong tissues. Episiotomy has some complications including perineal pain and discomfort, bleeding, infection, damage to anal sphincter and mucosa, wound opening, rupture expansion, difficulty in sitting and holding one's infant, disruption of maternal-infantile relationships, and reduction of sexual desire. Therefore, wound healing is of particular importance [3].

A study done by Pragati Nayak to assess the knowledge level and home management of minor ailments of puerperium among postnatal mothers in selected hospitals of Bangalore reported that $42 \%$ have inadequate, $43 \%$ have moderate, and only $17 \%$ of the subjects had adequate knowledge on minor ailments of puerperium [4].

A study was conducted in the village of Chhainsa Haryana, India, regarding selected minor ailments of puerperium shows that $64 \%$ are affecting with breast problems, $17 \%$ affecting with constipation, and $22 \%$ with fatigue [5]
The minor ailments of puerperium are the minor discomforts faced by the women during puerperium. The impact of the events of labor and birth and transition from nonparenthood to parenthood brings physical disorder and depression. The management of minor disorders prevents the risk of severe forms of postpartum disorder. Minor ailments of puerperium which commonly found in postnatal mothers are afterpain, constipation, abdominal tenderness, burning on urination, edema on legs, diuresis, perineal pain, and breast engorgement [6]. In this study, there searchers assessed minor ailments of puerperium. The objective of the study was identified the incidence and knowledge of minor ailments of puerperium among postnatal mothers and to develop an information leaflet on the management of minor ailments of puerperium.

\section{METHODS}

The present study used the quantitative approach with descriptive design and convenience sampling technique. With these methods, the researcher selected 100 postnatal mothers attending Obstetrics and Gynecology ward, AIMS, Kochi. Population: Target population were all the postnatal mothers attending obstetrics and gynecology department and accessible population were all postnatal mothers in the obstetrics and gynecology ward during the period of data collection. There were a total of 100 samples that are within 7 days after delivery.

\section{RESULTS}

The study showed that the major problems found among postnatal mothers are afterpain, perineal discomfort, constipation, and fatigue. Majority of the subjects had average knowledge, some had good knowledge, and only a few have poor knowledge. In this study, the postnatal mothers are divided into two groups based on the postnatal days such as one group belongs between 1 and 3 days and other group belongs to 4-7 days. 
Fig. 1 shows the percentage distribution of minor ailments of puerperium. Among postnatal mothers of 1-7 days, $67 \%$ of postnatal mothers having afterpain, 50\% having perineal discomfort, $43 \%$ of postnatal mothers having constipation, and $67 \%$ having fatigue.

Fig. 2 shows the percentage distribution of afterpain. Among postnatal mothers within 1-3 days, afterpain is $55 \%$ and within $4-7$ days, it is $12 \%$ and not having afterpain is $22 \%$ and $11 \%$, respectively.

Fig. 3 shows the percentage distribution of perineal discomfort among postnatal mothers. Within 1-3 days, perineal discomfort is $42 \%$ and within $4-7$ days, it is $18 \%$ and not having discomfort is $35 \%$ and $5 \%$, respectively.

Fig. 4 shows the percentage distribution of constipation among postnatal mothers. Within 1-3 days, constipation is 38\% and within 4-7 days, it is $5 \%$ and not having constipation is $39 \%$ and $18 \%$, respectively.

Fig. 5 shows the percentage distribution of fatigue among postnatal mothers. Within 1-3 days, fatigue is $53 \%$ and within $4-7$ days, it is $14 \%$ and not having fatigue is $24 \%$ and $9 \%$, respectively.

Table 1 summarizes the incidence of other minor ailments among postnatal mothers within 1-3 days and within 4-7 days and also, mothers not having minor ailments also shown in this Table 1.

Data presented in Fig. 6 represents the knowledge level of postnatal mothers regarding minor ailments of puerperium. Majority of the subjects had average knowledge (65\%), some of them have good knowledge (21\%), and only few of them have poor knowledge (14\%).

\section{DISCUSSION}

Puerperium is defined as the time from the delivery of the placenta through the first few weeks after the delivery. This period is usually considered to be 6 weeks in duration [7]. By 6 weeks after delivery, most of the changes of pregnancy, labor, and delivery have resolved and the body has reverted to the nonpregnant state [8].

A report of the WHO, 2010, shows that 90 (96\%)of women are getting at least one physical health symptoms postnatally. The morbidity rate of mother in puerperium is very high. Among this, $71.4 \%$ are affecting with breast problems, $61.7 \%$ with constipation, $86.6 \%$ with fatigue, and $80.4 \%$ with insomnia. Postpartum perineal pain has reported to be affecting $42 \%$ of women within the first 2 weeks after their vaginal delivery [9].

In the present study, overall data shows that major problems found among postnatal mothers are afterpain, perineal discomfort, constipation, and fatigue. Majority of the subjects had only average level of knowledge regarding the minor ailments of puerperium.

The above two studies show that the common postnatal problems found in postnatal mothers are afterpain, perineal discomfort, constipation, and fatigue. If these minor ailments are not properly managed, it may adversely affect the mother. Therefore, proper care and management of these ailments must be carried out. Focus in developing countries should shift improving awareness about the identification of minor ailments and their treatment modalities [10].

Childbirth is one of the most precious times in the life of women. Ayurveda, the traditional medicinal system of India, offers a detailed diet therapy for postpartum healthcare to rejuvenate women's health [11]. Hence, postnatal mothers also have to incorporate traditional ayurvedic remedies also to manage minor ailments of puerperium.

The major findings of the study include the incidence of minor ailments among postnatal mothers within 7 days and also revealed the knowledge

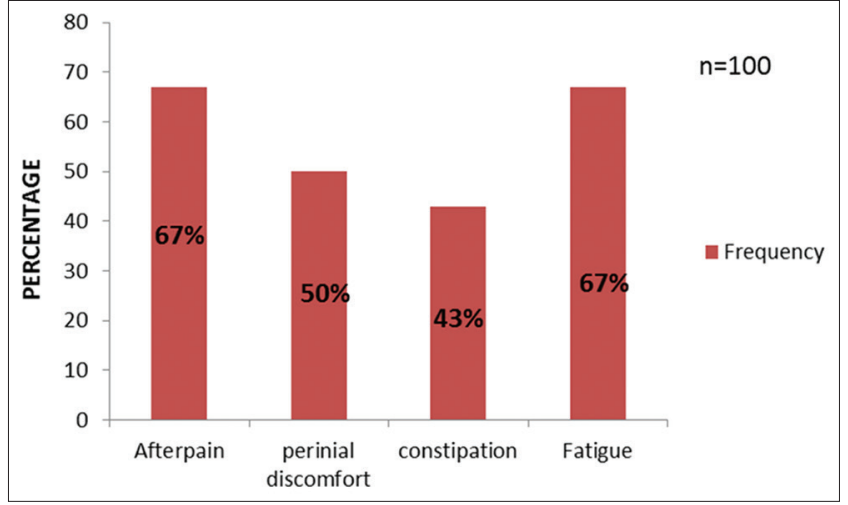

Fig. 1: Incidence of minor ailments of puerperium in 1-7 days

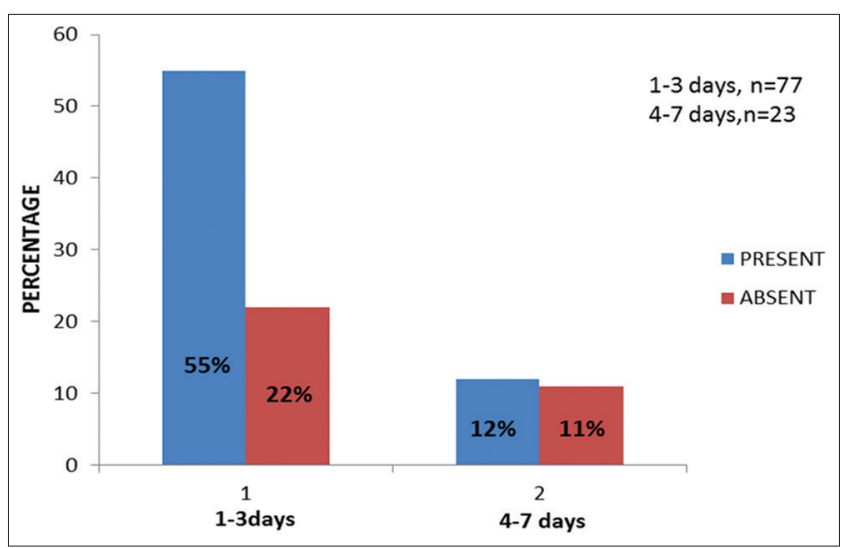

Fig. 2: Incidence of afterpain among postnatal mothers

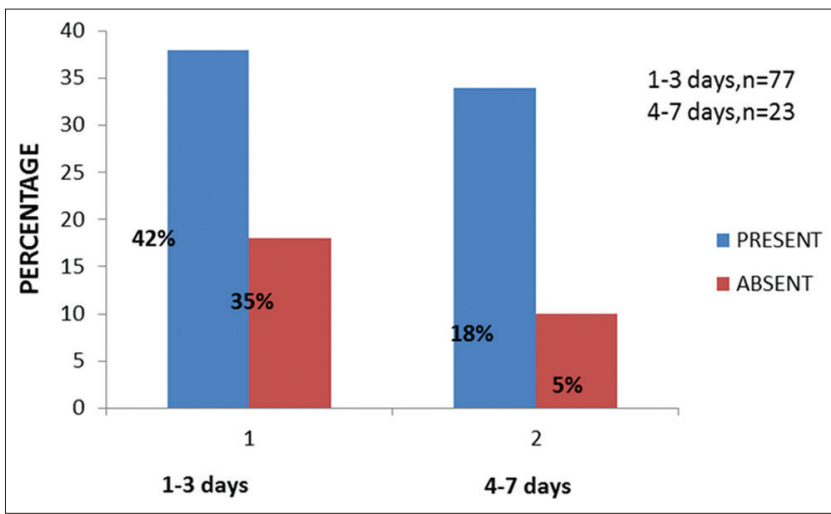

Fig. 3: Incidence of perineal discomfort among postnatal mothers

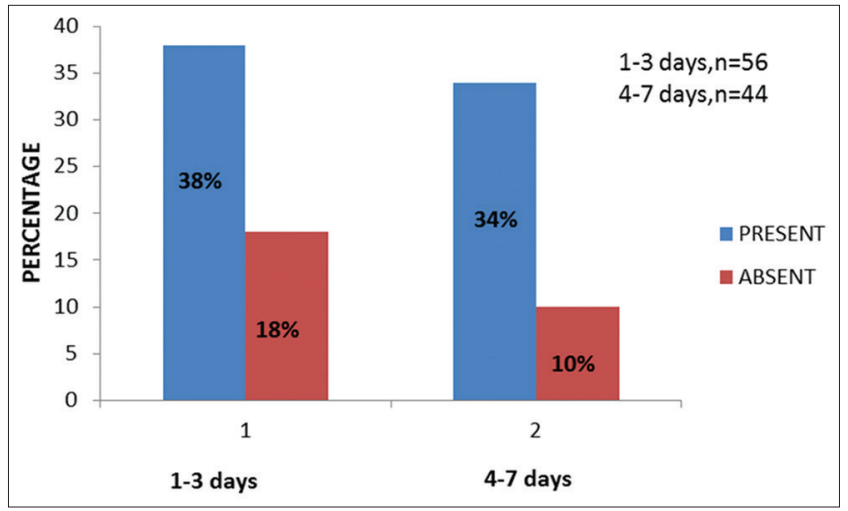

Fig. 4: Incidence of constipation among postnatal mothers 
Table 1: The incidence of minor ailments in postnatal mothers

\begin{tabular}{|c|c|c|c|c|c|c|c|c|}
\hline Problems & $\begin{array}{l}\text { Burning on } \\
\text { urination }\end{array}$ & $\begin{array}{l}\text { Urinary } \\
\text { incontinence }\end{array}$ & $\begin{array}{l}\text { Edema } \\
\text { on legs }\end{array}$ & $\begin{array}{l}\text { Breast } \\
\text { engorgement }\end{array}$ & $\begin{array}{l}\text { Cracked } \\
\text { nipples }\end{array}$ & Mastitis & $\begin{array}{l}\text { Insufficient milk } \\
\text { production }\end{array}$ & Hemorrhoids \\
\hline \multicolumn{9}{|l|}{ Frequency } \\
\hline \multicolumn{9}{|l|}{ 1-3 days } \\
\hline Present & 19 & 10 & 28 & 12 & 5 & 1 & 29 & 2 \\
\hline Absent & 58 & 67 & 49 & 65 & 72 & 76 & 48 & 75 \\
\hline \multicolumn{9}{|l|}{ 4-7 days } \\
\hline Present & 17 & 1 & 12 & 3 & 1 & 0 & 5 & 2 \\
\hline \multicolumn{9}{|l|}{ Percentage } \\
\hline \multicolumn{9}{|l|}{ 1-3 days } \\
\hline Present & 24.7 & 13 & 36.4 & 15.6 & 6.5 & 1.3 & 37.7 & 2.6 \\
\hline Absent & 75.3 & 87 & 63.6 & 84.4 & 93.5 & 98.7 & 62.3 & 97.4 \\
\hline \multicolumn{9}{|l|}{ 4-7 days } \\
\hline Present & 26.1 & 4 & 52.2 & 13 & 4.3 & 0 & 21.7 & 8.7 \\
\hline Absent & 73.9 & 95.7 & 47.8 & 87 & 95.7 & 100 & 78.3 & 91.3 \\
\hline
\end{tabular}

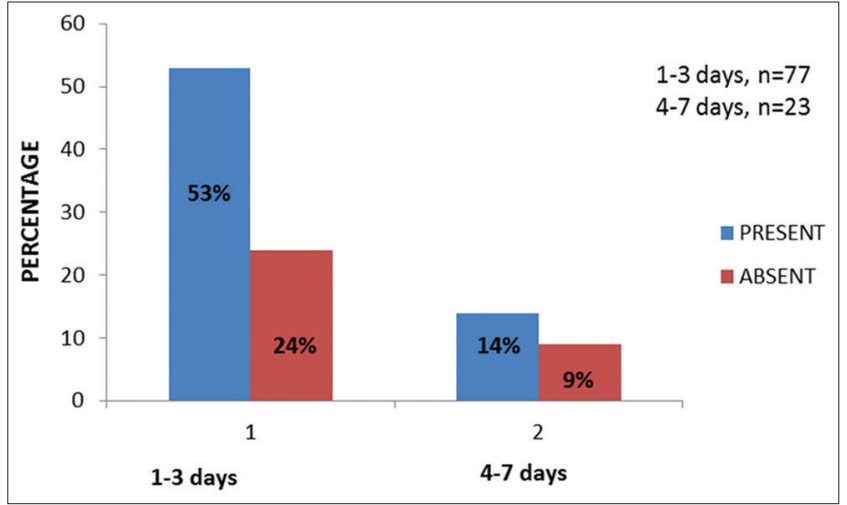

Fig. 5: Incidence of fatigue among postnatal mothers

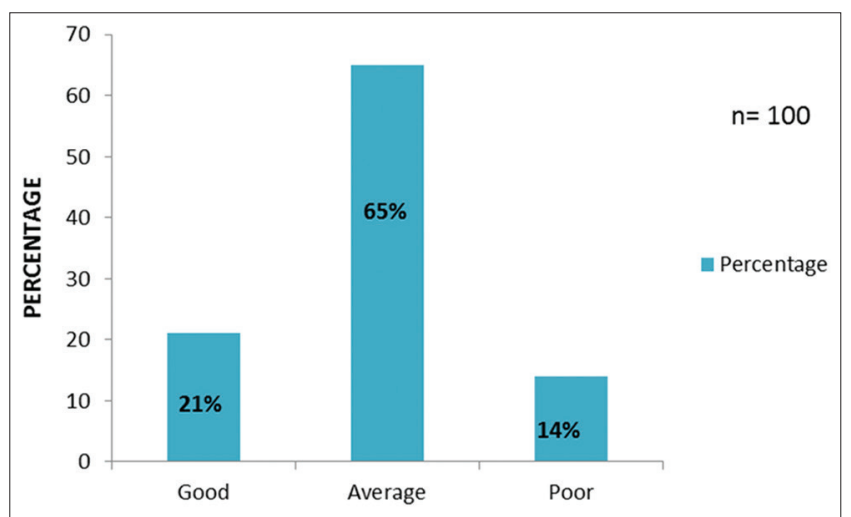

Fig. 6: Knowledge regarding minor ailments of puerperium in postnatal mothers

among postnatal mothers on the management of minor ailments of puerperium. The strength of this study is that after identifying incidence and knowledge of minor ailments of puerperium, researchers provided baseline information leaflet on the management of minor ailments of puerperium that leads to acquire average knowledge regarding the management of minor ailments.

\section{CONCLUSION}

The study showed that majority of postnatal mothers experienced the postnatal minor ailments such as afterpain, perineal discomfort, constipation, and fatigue. The majority of the postnatal mothers had average knowledge level. It is concluded that health education should be provided to all the postnatal mothers regarding minor ailments of puerperium and its management. Providing empathetic and sound advice about measures through a leaflet to relive these discomforts helps promote overall health and well-being.

\section{REFERENCES}

1. Basavanthapa BT. Text Book of Midwifery and Reproductive Health. $1^{\text {st }}$ ed. New Delhi: Jaypee Brothers Publisher; 2006

2. WHO.WHORecommendationonPostnatalCareoftheMothesandNewborn. Available from: http://www.postpartumwikipediathefreeencyclopedia. [Last retrieved on 2014 Dec 22]

3. Kaviani M, Sepasi S, Asima S, Emamghoreishi M, Azadi N, Haghpanah S. The effects of olive leaf extract oinment on pain intensity and early maternal complication in primiparous women. Int J Pharm Pharm Sci 2017:9:31-4.

4. Devi SN. Prevention of puerperal infection. Nurses India 2008;15.9:4-6.

5. Medical Research Study Report Regarding Selected Minor Ailments of Puerperium in Chains, Haryana, India. Available from: http://www. rguh.ac.in/cdc/onlinecdc/uploads/05-N216-33941.doc.

6. Nayak P. Thesis on a Study to Assess the Knowledge Level and Home Management of Minor Ailments of Puerperium among Postnatal Mothers in Selected Hospitals, Bangalore, Nursing and Midwifery Research; 2010. p. 16-7.

7. Bhide AG, Pathki AS, Levi JM. Text Book of Obstretics for Nursing and Midwifery. $1^{\text {st }}$ ed. New Delhi: Jaypee Brothers Publisher; 2000.

8. Popovic JR. 1999 National Hospital Discharge Survey: Annual summary with detailed diagnosis and procedure data. Vital Health Stat 13 2001;151:i-v, 1-206.

9. Kent JC, Ashton E, Hardwick C, Rowan MK, Fairclough KC, Menon LL, et al. Nipple Pain in Breast Feeding Mothers: Incidence; 2010. Available from: http://www.worldhealthorganisation.org/prev./ morbidity.

10. Vaidyanathan B, Kumar S, Sudhakar A, Kumar RK. Conotruncal anomalies in the fetus: Referral patterns and pregnancy outcomes in a dedicated fetal cardiology unit in South India. Ann Pediatr Cardiol 2013;6:15-20.

11. Jaina N, Goyala S, Ramawata KG. Evaluation of antioxidant properties and total phenolytic content of medicinal plants used in diet therapy during post-partum healthcare in Rajasthan. Int J Pharm Pharm Sci 2011;3:248-53. 